\title{
THE STRUCTURE OF THE TETRA-POTASSIUM SALT OF CALIX[4]ARENE DIHYDROXYPHOSPHONIC ACID ${ }^{\S}$
}

\author{
Adina N. Lazar,* a Oksana Danylyuk, ${ }^{\mathrm{b}}$ Kinga Suwinska, ${ }^{\mathrm{b}}$ and Anthony W. Coleman ${ }^{\mathrm{a}}$ \\ ${ }^{a}$ Institut de Biologie et Chimie des Protéines, CNRS UMR 5086, 7 passage du Vercors, F-69367 Lyon cedex 07, France \\ ${ }^{b}$ Institute of Physical Chemistry, Polish Academy of Sciences, Kasprzaka, 44/52, PL-01 224 Warszawa, Poland \\ *E-mail: a.lazar@bo.ismn.cnr.it; Fax: +48223433333
}

\begin{abstract}
The solid-state structure of the tri-potassium calix[4]arene dihydroxyphosphonate salt is presented. In this structure, two potassium cations bridge between layers of dimeric calixarene diphosphonate units and two other potassium cations bridge along the face of the layers. The ubiquitous dimeric association of the calixarenes shows the highest interdigitation value so far observed. As expected, the cations are solvated and are complexed exo with respect to calixarene crown. The octahedral coordination sphere of the potassium cations is formed by two phosphonate groups of the calixarenes and four water molecules. Electrostatic forces represent the major element of interaction in the solid-state system.
\end{abstract}

Keywords: Calixarenes, cation binding, electrostatic interactions.

\section{INTRODUCTION}

Complexation of small molecules or ions by calixarenes is a subject of wide interest, which has been the basis for a large body of work in the past few years. The calixarenes have been widely used in binding various metal cations [1-3], aromatic ammonium and alkyl cations [4,5] or acetylcholine [4-6].

An extraordinary versatility has been shown by these macromolecules as metal binding agents, supramolecular systems being formed with metals belonging to all groups in the periodic table [7-9]. Previous studies showed that calix[4]arenes are efficient binders for different alkali and alkaline-earth cations. Small cations, like such as $\mathrm{Li}^{+}$and $\mathrm{Na}^{+}$ are complexes as guest molecules in the aromatic cavity of the calixarene (endo complexation), whereas the larger ones $\left(\mathrm{Rb}^{+}\right.$and $\left.\mathrm{Cs}^{+}\right)$do not fit in the calixarene cavity, existing as complexes exo with respect to the aromatic core.

Nevertheless, the complexation of the cations depends not only on their size, but also on the nature of the solvent used. Thus, for apolar solvents, in the case of neutral calixarene molecules, the complexation of cations is endo. For polar solvents, the complexation is exo, the cation being located outside the cone of the host molecule, close to the oxygen atoms of the lower rim [4].

The recognition properties can be fine-tuned through modification of the phenolic lower rim. Substitution at the phenolic oxygens are performed in order to render the host molecules more soluble or more complimentary with respect to guest molecules.

A large range of ion-complexing calix[n]arenes have been studied, since Mc Kervey [5], but no such abilities have been yet reported for the calix[4]arene dihydroxyphosphonic acid. This water-soluble calixarene derivative has proved to have strong complexation capacity with regard to organic amonium cations. Thus a wide variety of packing motifs have been observed in the solid state complexes of this derivative with both aromatic and aliphatic ammonium cations [10-12]. It is obvious that the anionic aspect of the calix[4]arene dihydroxyphosphonic acid facilitates the non-covalent interactions with positively charged molecules.

In this paper we present the first example of a metal cation, potassium, complexed by calix[4]arene dihydroxyphosphonic acid.

\section{EXPERIMENTAL SECTION}

Crystal Growth

Calix[4]arene dihydroxyphosphonic acid (1) was synthesised according to the literature [13]. A solution of $0.01 \mathrm{M}$ of $\mathbf{1}$ was prepared in methanol. In order to set up the $\mathrm{pH}$ of this solution at a neutral value (pH 7), careful neutralisation was applied, using $\mathrm{KOH}$.

Crystals were grown from this solution, by slow evaporation at room temperature.

$X$-Ray diffraction

The intensity data were collected with a Nonius KappaCCD diffractometer (MoK $\alpha$ radiation $\lambda=0.71073 \AA, 100(2) \mathrm{K})$. All the collected data were corrected for Lorentzand polarisation effects but not for absorption. The

\footnotetext{
$\S$ Material presented at the XV-th Conference "Physical Methods in Coordination and Supramolecular Chemistry", September 27 October 1, 2006, Chişinău, Moldova.
} 
direct methods technique and Fourier techniques (SHELXS-86) [14] were employed in order to solve the structure and the refinements were done on $|\mathrm{F}|^{2}$ (SHELX-97) [15]. H-atoms were placed in geometric positions.

\section{RESULTS AND DISCUSSION}

In this paper we present the first result of cations binding by calix[4]arene dihydroxyphosphonic acid, where the major driving force is the attraction between oppositely charged molecules.

\section{Crystal data of the complex of 1 with potassium cations}

\begin{tabular}{|c|c|}
\hline Compound & C4diP-K \\
\hline Formula & $\mathrm{C}_{28} \mathrm{H}_{24} \mathrm{O}_{10} \mathrm{P}_{2} \cdot 2 \mathrm{~K} \cdot \mathrm{CH}_{3} \mathrm{OH} \cdot 11 \mathrm{H}_{2} \mathrm{O}$ \\
\hline FW & 890.83 \\
\hline Temperature, $\mathrm{K}$ & $100(2)$ \\
\hline Color & Colorless \\
\hline Crystal size, $\mathrm{mm}$ & $0.25 \times 0.15 \times 0.10$ \\
\hline Crystal system & Monoclinic \\
\hline Space group & $\mathrm{P} 2 / \mathrm{c}$ \\
\hline $\mathrm{a}, \mathrm{b}, \mathrm{c} \AA$ & $15.5758(7) ; 13.0023(7) ; 19.385(1)$ \\
\hline$\beta^{\circ}$ & $111.067(4)$ \\
\hline $\mathrm{V}, \AA^{3}$ & $3663.5(3)$ \\
\hline $\mathrm{Z}$ & 4 \\
\hline 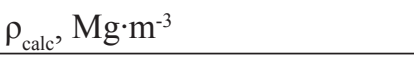 & 1.615 \\
\hline $\mathrm{F}(000)$ & 1872 \\
\hline$\mu(\mathrm{MoK} \alpha) \mathrm{mm}^{-1}$ & 0.437 \\
\hline$\theta$ range for data collection, ${ }^{\circ}$ & 2.18 to 18.92 \\
\hline Reflections collected & 23811 \\
\hline Absorption correction & none \\
\hline Data / restraints / parameters & $2869 / 0 / 536$ \\
\hline Goodness-of-fit on $\mathrm{F}^{2}$ & 1.08 \\
\hline Final $\mathrm{R}$ indices $[\mathrm{I}>2 \sigma(\mathrm{I})]$ & $\mathrm{R}=0.089, \mathrm{wR}=0.216$ \\
\hline $\mathrm{R}$ indices (all data) & $\mathrm{R}=0.129, \mathrm{wR}=0.238$ \\
\hline Refinement method & Full-matrix least-squares on $\mathrm{F}^{2}$ \\
\hline
\end{tabular}

In the solid state structure of calix[4]arene dihydroxyphosphonic acid (Fig. 1a) with potassium cations, two molecules of 1 interact with six $\mathrm{K}^{+}$cations (Fig. 1b).

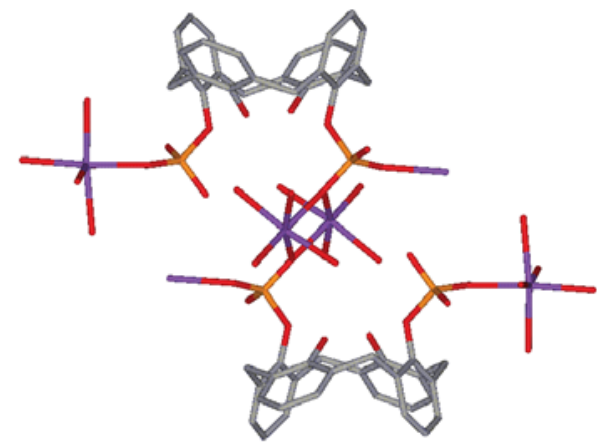

(a)

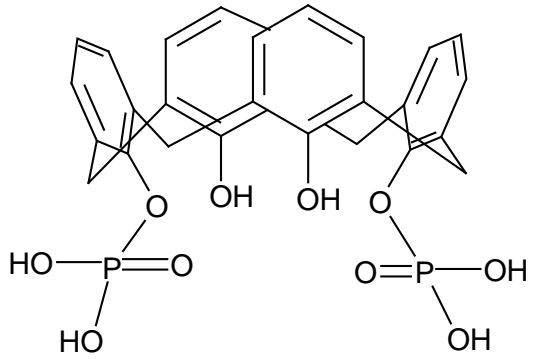

(b)

Fig. 1: (a) Scheme of 1; (b) Dimeric unit of the complex of $\mathbf{1}$ with $\mathrm{K}^{+}$; solvent molecules are excludes for the simplicity of the figure.

As in all the other structures implying the calix[4]arene dihydroxyphosphonic acid, the characteristic generic motif is the dimeric association of two molecules of calixarene (Fig. 2a). 


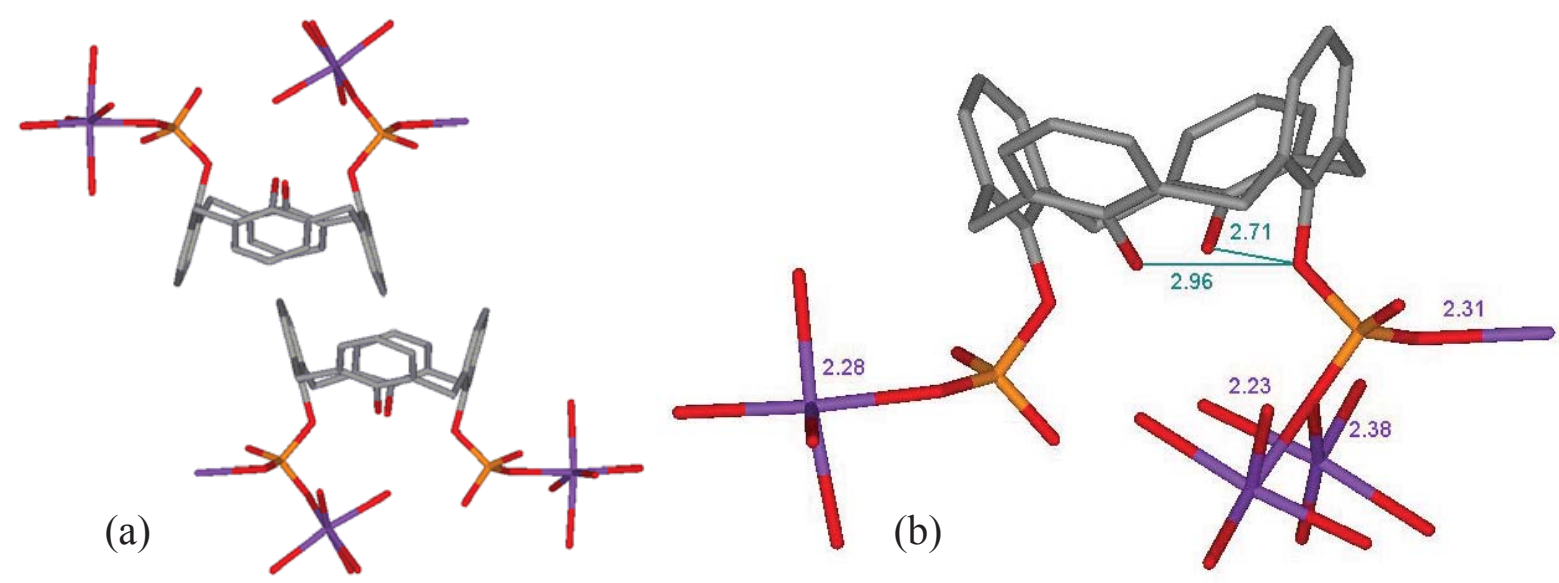

Fig. 2: (a) Interdigitation of the neighboring molecules of 1, (b) Intramolecular H-bonds in 1, (in green) and the electrostatic interactions with $\mathrm{K}^{+}$(values in blue).

Here, the interdigiting angle is $163.3^{\circ}$ and represents the highest value of interdigitation with respect to the previously reported structures: $158.8^{\circ}$ in the case of uncomplexed dimer [16] or $161^{\circ}$ in the complex with $4,4^{\prime}$ bipyridine [17].

The strong electrostatic interactions involving the phosphonate oxygens determine an opening of the hydrophobic core. The angles between opposite aromatic rings of 1 being of 30.9(4) ${ }^{\circ}$ and $105.2(4)^{\circ}$, notably bigger than in the case of uncomplexed calix[4] arene dihydroxyphosphonic acid, the latter structure presenting cone angles of $20.87^{\circ}$ and $77.97^{\circ}$. As a consequence, the intramolecular hydrogen bonds between the phenolic oxygens are shorter than in the reference structure: 2.71(1) and 2.96(1) compared to 2.92(2) and 3.05(1) $\AA$, respectively (Fig. 2b).

From a general point of view, the complex adopts a 1-D architecture based on layers of dimeric units characteristic to dihydroxyphosphonic calixarene, held together by the $\mathrm{K}^{+}$cations ion-paired with the deprotonated oxygen atoms of the phosphonate groups (Fig. 3). Thus, infinite bridges of electrostatic interactions are connecting the dimeric units of 1. A stepped like organization is observed, as represented in Fig. 3a, with distances between the layers of $15.6 \AA$ and between each dimeric unit of $13.0 \AA$. A perpendicular view to this motif shows the parallel packing of these sheets of dimers (Fig. 3b).
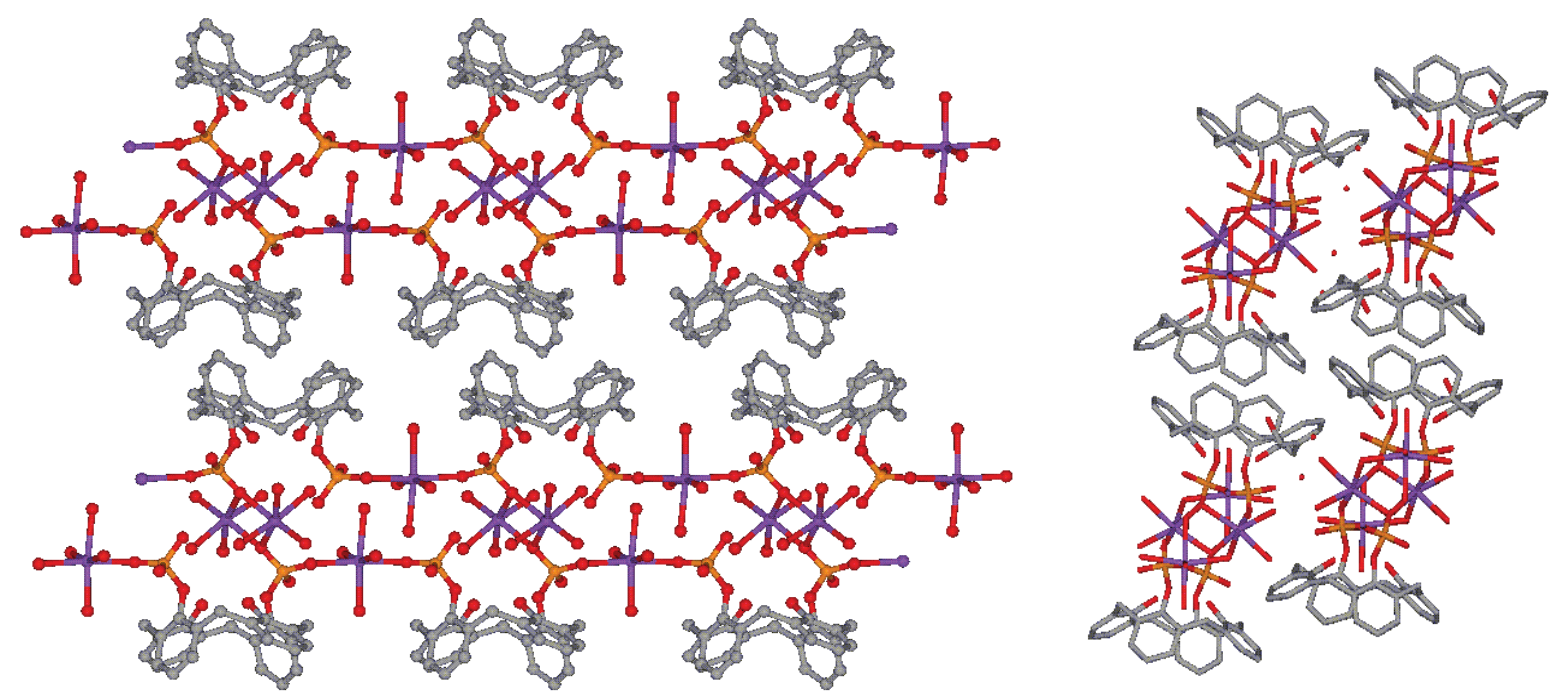

(a)

(b)

Fig. 3: (a) - View of the packing along c axis; (b) - View of the double chains along $\mathbf{b}$ axis.

The electrostatic interactions between the phosphonate oxygens and $\mathrm{K}^{+}$are multiple, the closed distances being: 2.24(1), 2.285(9), 2.31(1), and 2.38(1) 2.88(1) A (see Fig. 2b). Eight water molecules are coordinated to the complex, by electrostatic interactions. Some of them form hydrogen bonds with phenolic oxygens or to oxygens of the phosphonate groups of $\mathbf{1}$, while some other are hydrogen bonded between them (see Tab. 2). 


\begin{tabular}{|c|c|c|c|c|c|}
\hline \multicolumn{6}{|c|}{ Selected interactions: } \\
\hline Interaction & Water*..water & Water $\cdots \mathbf{K}^{+}$ & OH*WWater & OP...Water & $\mathbf{O P} \cdots \mathbf{K}^{+}$ \\
\hline Electrostatic & - & $\begin{array}{ll}\mathrm{K} 1 \cdots \mathrm{O} 1 \mathrm{~W} & 2.28(1) \\
\mathrm{K} 1 \cdots \mathrm{O} 2 \mathrm{~W} & 2.25(2) \\
\mathrm{K} 1 \cdots \mathrm{O} 3 \mathrm{~W} & 2.27(1) \\
\mathrm{K} 1 \cdots \mathrm{O} 4 \mathrm{~W} & 2.33(2) \\
\mathrm{K} 2 \cdots \mathrm{O} 5 \mathrm{O} & 2.32(1) \\
\mathrm{K} 2 \cdots \mathrm{O} 6 \mathrm{~W} & 2.31(1) \\
\mathrm{K} 2 \cdots \mathrm{O} 7 \mathrm{~W} & 2.32(1) \\
\mathrm{K} 2 \cdots \mathrm{O} 8 \mathrm{~W} & 2.43(1)\end{array}$ & - & - & $\begin{array}{ll}\mathrm{K} 1 \cdots \mathrm{O} 2 \mathrm{~A} & 2.88(1) \\
\mathrm{K} 1 \cdots \mathrm{O} 4 \mathrm{~A} & 2.386(1) \\
\mathrm{K} 1 \cdots \mathrm{O} 4 \mathrm{~A} & 2.238(3) \\
\mathrm{K} 2 \cdots \mathrm{O} 2 \mathrm{C} & 2.285(9) \\
\mathrm{K} 2 \cdots \mathrm{O} 2 \mathrm{~A} & 2.31(1)\end{array}$ \\
\hline H-bonds & 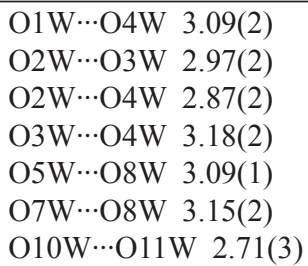 & - & 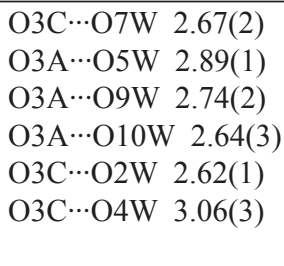 & 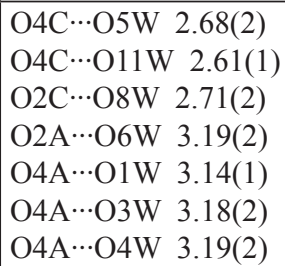 & - \\
\hline
\end{tabular}

Three other water molecules, plus a methanol molecule hydrogen bond with phenolic oxygens or with the coordinated solvent molecules. Selective values of non-covalent interactions are presented in Tab. 2.

\section{CONCLUSION}

Apparently simple, the solid state structure of calix[4]arene dihydroxyphosphonic acid presents a high degree of complexity, from the point of view of non-covalent interactions present in the complex, of the architecture achieved and of the effective cationic binding. As expected, ion pairing between phosphonate oxygen atoms and potassium cations dominate the forces driving the structural integrity.

\section{ACKNWLEDGEMENTS}

This research was partially supported by the Polish Ministry of Science and Information Society Technologies

(Grant 4 T09A 068 25).

\section{REFERENCES}

[1] P. C. Kearney, L. S. Mizoue, R. A. Kumpf, J. E. Forman, A. McCurdy, D. A. Dougherty, J Am Chem Soc., , 1993, $115,9907$.

[2] A. Ikeda, S. Shinkai, Chem Rev., 1997, 1713.

[3] A. Ikeda, S. Shinkai S, J. Am. Chem. Soc., 1994, 116, 3102.

[4] S. Kumar, G. Hundal, D. Paul,M. S. Hundal, H. Singh, J. Org. Chem., 1999, 64, 7717.

[5] F. Arnaud-Neu, G. Barrett, D. Corry, S. Cremin, G. Ferguson, J. F. Gallagher, S. J. Harris, M. A. McKervey M. J. Schwing-Weill,, J Chem Soc Perkin 2, 1997, 575.

[6] R. Arnecke, V. Böhmer, R. Cacciapaglia, A. D. Cort, L. Mandolini, Tetrahedron, 1997, 53, 4901.

[7] G. Arena, A. Casnati, A. Contino, G. G. Lombardo, D. Sciotto, R. Ungaro, Chem Eur J., 1999, $5,738$.

[8] V. Bohmer, Kluwer Academic, Dordrecht, 1991.

[9] J. Vicens, Z. Asfari, J.M. Harrowfield, Calixarenes 50 th Anniversary: Commemorative Volume, Kluwer Academic, Dordrecht, 1995.

[10] A. W. Coleman, E. Da Silva, F. Nouar, M. Nierlich, A. Navaza, J. Chem. Soc. Chem. Commun., 2003, $7,826$.

[11] B. Rather, B. Moulton, M. J. Zaworotko, F. Perret, N. Morel-Desrosiers, E. Da Silva, A. W. Coleman, Crystal Engineering, 2003, 6, 15.

[12] A. N. Lazar, A. Navaza, A. W. Coleman, Chem. Commun., 2004, 1052.

[13] V. I. Kalchenko, J. Lipkowski, Y. A. Simonov, M. A. Vysotsky, K. Suwinska, A. A. Dvorkin, V. V. Pirozhenko, I. F. Tsimbal, L. N. Markovsky.- Zh. Obshch. Khim., 1995, 65, 1311-1320.

[14] G. M. Sheldrick, Acta Cryst. A, 1990, 46, 467-473.

[15] G. M. Sheldrick,, SHELXL-97. Program for the Refinement of Crystal Structures. Univ. of Goettingen, Germany. 1997.

[16] Lipkowski, Y. Simonov, V. I. Kalchenko, M. A. Vysotsky, L. N. Markovsky, Anales de Quimica Int. Ed., 1998, 94, 328-331.

[17] A. N. Lazar, N. Dupont, A. Navaza, A. W. Coleman, Crystal Growth and Design, 2006, 6, 669-674. 